\title{
Consolidación de derechos territoriales y marítimos en el Ártico: Análisis de una práctica histórica e interrumpida de resolución pacífica para el goce efectivo de los derechos
}

\author{
CONSOLIDATION OF TERRITORIAL AND MARITIME RIGHTS IN THE ARCTIC: ANALYSIS \\ OF A HISTORIC AND UNINTERRUPTED PRACTICE OF PACIFIC RESOLUTION FOR THE \\ EFFECTIVE ENJOYMENT OF RIGHTS
}

\section{Giovanny Vega-Barbosa*}

\begin{abstract}
ResUMeN
El presente escrito aborda el proceso histórico de construcción del régimen jurídico que gobierna el ejercicio de soberanía en las tierras e islas árticas, así como el proceso vigente y pendiente para la consolidación de los derechos soberanos sobre la plataforma continental más allá de las 200 millas náuticas. Como hipótesis de trabajo, el autor plantea que las actuales reclamaciones a una plataforma continental extendida se inscriben y sustancian en concordancia con la postura adoptada por los Estados árticos para la definición de sus títulos sobre las tierras e islas árticas. El artículo tiene como propósito complementar la literatura existente en la materia visibilizando la existencia de una verdadera práctica histórica e interrumpida de solución pacífica de las controversias más importantes.
\end{abstract}

\section{ABSTRACT}

This article addresses the historic process leading to the construction of a legal regime governing the exercise of sovereignty over the arctic lands and islands as well as the current and pending process for the consolidation of sovereign rights over the continental shelf beyond 200 nautical miles. As his main working hypothesis, the author submits that the current claims to an extended continental shelf can be framed and are substantiated coherently with the approach adopted for the definition of territorial titles of the lands and islands in the Arctic. This articles seeks to complement the current literature by visualizing the existence of a real historic artic practice of peaceful settlement of the most important disputes.

\section{Palabras Clave}

Océano Ártico, solución pacífica, territorio, plataforma continental más allá de las 200 millas náuticas, Comisión de Límites de la Plataforma Continental, cooperación

\footnotetext{
* Director del Grupo de Investigación sobre el Derecho del Mar y Profesor Titular de la Cátedra de Derecho Internacional Público de la Facultad de Jurisprudencia de la Universidad del Rosario (Bogotá D.C., Colombia). Directed Studies-Hague Academy of International Law (2013). Correo electrónico: giovanny.vega@urosario.edu.co. Dirección postal: Cll 57 No 3-42 (504)-Bogotá, Colombia.
} 
KEY WORDS

Arctic Ocean, pacific settlement, territory, continental shelf beyond 200 nautical miles, Commission on the Limits of the Continental Shelf, cooperation

\section{Introducción}

La configuración geográfica del Océano Ártico lo convierte en el único lugar en la Tierra en donde las fronteras marítimas de los cinco Estados convergen en un solo punto: el Polo Norte. Por esta razón, las controversias marítimas entre los Estados árticos no constituyen un extraño y, por el contrario, son asuntos que ocupan un lugar importante en las políticas exteriores de sus Cancillerías ${ }^{1}$.

Sin perjuicio de lo anterior, en la actualidad el Ártico es un escenario relativamente estable en relación con las reivindicaciones territoriales y marítimas ${ }^{2}$. Esto, porque a la fecha las áreas continentales con proyección al Océano Ártico y la inmensa mayoría de sus islas han sido adjudicadas a uno de los Estados árticos bajo modos que el derecho internacional público reconoce como válidos.

Este estado de calma está precedido por importantes discusiones territoriales que se vieron avivadas por la creatividad de las construcciones conceptuales, conforme a la cuales esos Estados procuraron hacerse soberanos sobre las tierras árticas y así ejercer otros derechos sobre las aguas del Océano Ártico. En todo caso, a pesar de la importancia de los intereses concernidos y el momento histórico en el que se inscribieron las reivindicaciones, fueron pocas las instancias de amenaza e inexistente las de uso efectivo de la fuerza. Por el contrario, los Estados árticos procuraron avanzar sus intereses a través de teorías jurídicas novedosas inspiradas en los rigores y dificultades del área.

Canadá sería pionero en la estructuración de teorías jurídicas para apoyar la reivindicación de porciones de territorio discernibles en la distancia y concebibles en el imaginario, pero inaccesibles en la práctica ${ }^{3}$. La entonces Unión de Repúblicas Socialistas Soviéticas (URSS) elaboraría en donde las construcciones canadienses se habían quedado cortas, Ilegando a proclamar la denominada "Teoría de los Sectores"

Una vez consolidados los títulos territoriales, la imposibilidad de acceso generada por la extensión y permanencia de los hielos del Océano Ártico tendría por consecuencia que, más allá de la importancia que se le asignó durante la

\footnotetext{
1 Shusterich (1984), p. 237; Feder (1978), pp. 801-809; LakHTine (1930), p. 703.

${ }^{2}$ Grant (2010), pp. 193-246.

${ }^{3}$ Pharand (2009), p. 10.

${ }^{4}$ BUTLER (1978), p. 72.
} 
Guerra Fría ${ }^{5}$, esta región del globo no fuera objeto de mayor atención dentro de la definición de las estrategias geopolíticas y comerciales de los Estados árticos. Sin embargo, el calentamiento global y sus efectos han suscitado acaloradas discusiones contemporáneas en relación con el acceso a los recursos del Ártico y el tránsito marítimo por sus aguas ${ }^{6}$.

En relación con los recursos naturales, recientemente Estados como China, Corea del Sur, Japón e Italia han alegado que el Océano Ártico constituye patrimonio común de la humanidad y, por lo tanto, pese a no ser Estados costeros con proyección a este, tienen derecho a beneficiarse de sus recursos naturales vivos y no vivos ${ }^{7}$. En lo que concierne al tránsito, el deshielo hace inminente el acceso de buques a través de rutas como el Paso Noroccidental, posibilidad altamente beneficiosa, pues recorta en casi 9.000 kilómetros la distancia a recorrer para pasar del Océano Atlántico al Océano Pacífico ${ }^{8}$. También se reabren discusiones territoriales ante la visualización de islas previamente cubiertas por el hielo ${ }^{9}$.

De otra parte, la reducción del grosor del hielo y la nueva posibilidad de acceso han propulsado iniciativas para la recolección de información científica sobre la plataforma continental del Océano Ártico. Al respecto, corresponde indicar que aunque este océano es comparativamente el menos extenso y cubre solo el 3\% de la superficie de la Tierra -en contraste con el Océano Pacífico, que cubre aproximadamente el $31 \%$-, debajo de sus aguas se encuentra más de un cuarto de la plataforma continental del planeta ${ }^{10}$. Esta característica permite incluir a los Estados árticos entre aquellos con las plataformas continentales más prolongadas ${ }^{11}$.

Desde el plano estrictamente normativo, la Convención de Naciones Unidas sobre el Derecho del Mar de 1982 (la Convención) marca un referente

${ }^{5}$ Durante la denominada Guerra Fría el Océano Ártico tuvo una especial relevancia geopolítica y militar al constituir la ruta más corta entre Estados Unidos de América y la entonces Unión de Repúblicas Socialistas Soviéticas. Chaturverdi (1996), p. 188.

${ }^{6}$ NeWTON (2005), pp. 321, 324.

7 Offerdal (2014), p. 90.

${ }^{8}$ JarASHOw et al. (2007), p. 1592. Sobre el incidente de 1985 entre Canadá y Estados Unidos de América en relación con el anuncio del USCG Polar Sea de cruzar el Paso Noroccidental, ver RothwELL (2013a), pp. 9-10.

${ }^{9}$ PotTs et al. (2008), p. 160.

${ }^{10}$ Estudios recientes señalan que el Océano Ártico contiene el 13\% de las reservas de petróleo no descubiertas del planeta y el 30\% de las reservas de gas aún por descubrir. Stauffer (2008).

${ }^{11}$ BAKer (2010a), p. 252. 
trascendental dentro de los propósitos de estabilidad geopolítica en el Ártico ${ }^{12}$. La Convención reconoció a todos los Estados costeros derechos soberanos y de jurisdicción mucho más extensos sobre el mar, inter alia, mediante la consagración de una zona económica exclusiva de hasta 200 millas náuticas contadas desde las líneas de base a partir de las cuales se mide la anchura del mar territorial ${ }^{13}$, y la posibilidad de reclamar una plataforma continental más allá de las 200 millas náuticas hasta el borde exterior del margen continental ${ }^{14}$.

Aunque en el contexto ártico son diversas las variables que exacerban el potencial desestabilizador de las reclamaciones más allá de las 200 millas náuticas, entre ellas, la extensión de la pretensión rusa y la imposibilidad de oponer el procedimiento del artículo 76 de la Convención a los Estados Unidos de América ${ }^{15}$, el presente escrito demostrará que, fiel a su tradición histórica, los Estados árticos están resolviendo sus diferencias de forma directa y, por sobre todo, a través de mecanismos pacíficos.

Como hipótesis principal el autor plantea que las actuales reclamaciones a una plataforma continental extendida se inscriben y sustancian en concordancia con la postura adoptada por los Estados árticos para la definición de sus títulos sobre las tierras e islas árticas. A la luz de lo anterior, se plantearon tres objetivos principales de investigación. En primer lugar, la demostración de una práctica consistente entre los Estados árticos de resolución pacífica de las controversias más importantes. En segundo lugar, identificar evidencia empírica sobre la influencia de las dinámicas territoriales pasadas en las presentes discusiones marítimas. Tercero, tener presente que, mediante la socialización de sus pretensiones y a través de la cooperación técnica y científica para la obtención de la evidencia requerida, los Estados árticos han elevado sus posibilidades de éxito frente a los rigurosos estándares previstos en el artículo 76 de la Convención para el establecimiento del borde exterior del margen continental, y por ende, para el goce efectivo de los derechos marítimos más allá del criterio de distancia.

El presente escrito se compone de cuatro partes principales. La primera parte expone el proceso de consolidación de los títulos sobre las tierras e islas en el Ártico (1). La segunda parte contiene consideraciones generales sobre la geografía relevante y el contenido del artículo 76 de la Convención (2). La tercera parte analiza la cuestión marítima contemporánea de mayor trascendencia en el

\footnotetext{
121833 UNTS 3.

131833 UNTS 3, artículo 57,

${ }^{14}$ BriLmayer et al. (2001), pp. 732-36.

${ }^{15}$ Ver MatLer (2005), p. 33.
} 
Océano Ártico, a saber, las reclamaciones sobre la plataforma continental más allá de las 200 millas náuticas (3). La cuarta parte introduce al lector a instancias recientes de tensión que ponen a prueba la tesis principal del autor, así como a las circunstancias que militan a favor de su confirmación (4). Finalmente, se exponen las conclusiones del autor.

\section{La consolidación de los títulos territoriales en el Ártico}

El derecho internacional ha desarrollado reglas sobre la forma en que el territorio se adquiere y se transfiere. Estas reglas se materializaron en modos que a su vez se categorizaron en dos subespecies principales: originarios y derivados ${ }^{16}$.

Los métodos originarios versan necesariamente sobre una terra nullius, es decir, una tierra que no pertenece a nadie en el momento en que se alega su descubrimiento ${ }^{17}$, y la cual puede ser apropiada mediante un hecho humano, inter alia, la ocupación efectiva de un espacio físico ${ }^{18}$, o mediante un hecho de la naturaleza, a saber, la accesión mediante un proceso lento, ininterrumpido y gradual denominado aluvión, o bien súbito, como la avulsión. La doctrina prevalente en el derecho internacional señala que el descubrimiento de una terra nullius es insuficiente por sí mismo para que esta pase a formar parte de los espacios bajo la soberanía de un Estado ${ }^{19}$. En el caso de los modos derivados, la adquisición del territorio es consecuencia de un acto jurídico como la cesión (gratuita u onerosa), la prescripción y la anexión y presupone la inexistencia de una terra nullius ${ }^{20}$.

En 1930, W. Lakhtine señaló en su célebre artículo "Rights over the Arctic" que las severas condiciones climáticas del Ártico no hacían viable acometer la apropiación soberana de sus islas conforme a los modos históricamente reconocidos $^{21}$. En un tal contexto, se comenzó a gestar una idea según la cual los

\footnotetext{
${ }^{16}$ Sharma (1997), p. 35; Shaw (2013), p. 151.

17 CIJ: Advisory Opinion, I.C.J. Reports 1975, p. 39, para. 79. Según fue expresado por la Corte, el concepto de terra nullius no es invocable en relación con territorios que aunque no están sometidos a la soberanía de un Estado, sí se encuentran habitados con una población con el suficiente grado de organización política como para oponerse a las pretensiones soberanas de un tercero.

${ }^{18}$ CIJ: Advisory Opinion, I.C.J. Reports 1975, p. 39, para. 79.

${ }^{19}$ Brownlie (1998), p. 144. En efecto, incluso las posiciones doctrinales más favorables a los efectos del descubrimiento o "anexión simbólica" reconocen que el título imperfecto ("inchoate title") así obtenido se perderá si no se acompaña con la ocupación efectiva de ese territorio. Award of 4 April 1928, pp. 839, 845.

${ }^{20}$ SHAW (2014), p. 360.

${ }^{21}$ Lakhtine (1930), p. 703.
} 
requisitos de la ocupación efectiva no eran aplicables en el Ártico y, por lo tanto, los Estados interesados se dieron a la tarea de estructurar y defender principios sustitutos. En relación con otras porciones de tierra con proyección al Océano Ártico de mayor extensión y fácil acceso, la cuestión legal más importante fue la de la oposición de títulos de diferente jerarquía.

La resolución de estas controversias determinaría lo que hoy podemos denominar "Estados árticos" desde una aproximación geográfica estricta. A este respecto, corresponde subrayar que aunque un sector de la doctrina caracteriza a Finlandia, Islandia y Suecia como Estados árticos ${ }^{22}$, desde un punto de vista territorial y al constatar que estos Estados no poseen salientes costeros hacia el Océano Ártico, esa posición no resulta ortodoxa ${ }^{23}$. Por ende, para efectos del presente trabajo se consideran Estados árticos a los Estados Unidos de América, Canadá, la Federación Rusa, el Reino de Dinamarca y el Reino de Noruega. Esto se entiende sin perjuicio de la participación activa de Finlandia, Islandia y Suecia en las cuestiones medioambientales del Ártico, especialmente en sede del Consejo Ártico ${ }^{24}$.

Serían dos las principales formulaciones jurídicas estructuradas para soportar las pretensiones territoriales sobre las tierras e islas en el Océano Ártico: la "Teoría de las regiones de atracción y contigüidad" y la "Teoría de los Sectores". Como veremos, no obstante la insuficiencia de estas teorías para consolidar derechos territoriales stricto sensu, estas fueron altamente relevantes para forjar los cimientos de las reclamaciones y contribuyeron a que las discusiones pudieran ser encauzadas por vías pacíficas.

En virtud de la teoría de la contigüidad, la soberanía de un Estado sobre una isla implica la extensión de esa soberanía a las islas vecinas ${ }^{25}$.

Por su parte, la primera formulación de la teoría de los sectores se atribuye al senador canadiense Pascal Poirier, quien de manera incipiente reclamó en 1907 derechos sobre las tierras e islas septentrionales situadas entre los $141^{\circ} \mathrm{y}$ $60^{\circ}$ oeste y ubicadas "dentro de la prolongación de los meridianos tangentes a los puntos más salientes, al Este y Oeste, de sus respectivos territorios" ${ }^{\prime 26}$. Leonid

\footnotetext{
22 Rayfuse (2007), p. 197; Rothwell (1996), p. 155.

${ }^{23}$ Las razones históricas que explican la situación actual responden, entre otras, a la imposibilidad de verificar islas dentro de las áreas de atracción de estos Estados y a procesos geopolíticos que derivaron en la pérdida de espacios con proyección al Océano Ártico. LAKHTINE (1930), p. 706.
}

24 "Declaration on the Establishment of the Arctic Council" (1996). Disponible en: https://oaarchive. arctic-council.org/handle/11374/85. [Visitado el 3.10.17]. El análisis sobre la importancia de la cooperación para la protección efectiva del medio ambiente ártico escapa al objeto del presente estudio. Sobre el particular, ver Young (2009), pp. 73-74; HeRTell (2009), p. 566.

${ }^{25}$ VÁsquez (1993), p. 252; LAKHTINE (1930), p. 705.

${ }^{26}$ Moreno-Quintana (1963), p. 322. 
Timtchenko resume la precitada formulación en los siguientes términos: “.. un país cuya posesión actual se extiende hasta las regiones del Ártico tendrá un derecho, o debería tener un derecho, o tiene un derecho, sobre todas las tierras que se encuentren en las aguas ubicadas entre una línea que se extiende por su extremo oriental Norte, y otra línea que se extiende por su extremo occidental Norte. Todas las tierras entre las dos líneas hasta el Polo Norte deberían pertenecer y pertenecen al país cuyo territorio colinda con el mismo" ${ }^{27}$.

Con esta primera aproximación a las teorías fundamentales, a continuación se describe el proceso de consolidación de los títulos sobre las tierras árticas.

\subsection{La consolidación de los derechos de Dinamarca}

Dinamarca ubicó en su zona de atracción o de influencia a Groenlandia. Históricamente y hasta la suscripción del Tratado de Kiel el 14 de enero de 1814 , la soberanía sobre Groenlandia le pertenecía a Noruega ${ }^{28}$. Las negociaciones diplomáticas entre los Estados se extenderían hasta el 9 de julio de 1924, fecha en la que se suscribiría un tratado por el cual Noruega reconoció la soberanía de Dinamarca sobre Groenlandia, pero retuvo derechos de pesca y caza en su costa occidental2 ${ }^{29}$.

En 1931 Noruega disputó la soberanía de Dinamarca sobre el sector oriental de Groenlandia mediante la promulgación de un decreto de 10 de julio de 1931. Noruega declaró de esta forma su ocupación del área denominada Eirik Raudes Land. En todo caso, la ocupación no se efectuó sin que de manera previa se agotaran algunas instancias de negociación ${ }^{30}$. Al considerar que su soberanía sobre Groenlandia ya estaba establecida y, por lo tanto, la ocupación noruega resultaba irrelevante e ilegal, Dinamarca le solicitó a la Corte Permanente de Justicia Internacional que declarara la ilegalidad de la proclamación y de todo acto posterior de ocupación ${ }^{31}$. La Corte determinó que ciertas ordenanzas y actos administrativos emitidos a mediados del siglo XVIII, inter alia, el

\footnotetext{
27 TimtChenko (1997), p. 29. Traducción en MarQués (2010), p. 46.

${ }^{28}$ Mediante el tratado se pone fin a las hostilidades entre Dinamarca y Suecia como parte de las Guerras Napoleónicas, y Dinamarca le cede Noruega a Suecia. El propósito era compensar parcialmente a Suecia por la pérdida de Finlandia y de las islas Åland ante Rusia en 1809. Antes del Tratado de Kiel, Noruega y Dinamarca habían permanecido unidas desde 1380. Ver "Treaty of Kiel". Disponible en: http://global.britannica.com/EBchecked/topic/317469/Treaty-of-Kiel [visitado el 3.10.2017].

${ }^{29}$ Ver Agreement between Denmark and Norway Concerning The East Greenland Fisheries. Disponible en: http://iea.uoregon.edu/pages/view_treaty.php?t=1967-DenmarkNorwayEastGreenlandFisheries. EN.txt\&par=view_treaty_html [visitado el 12.02.2017].

30 Sharma (1997), p. 76.

${ }^{31}$ PCIJ: Ser. A/B N 53,1933, pp. 23-24.
} 
establecimiento del monopolio sobre el comercio, se aplicaban a Groenlandia como un todo y sin distinción o aplicación fraccionada. La Corte señaló a continuación que, no obstante la imposibilidad de acceso, la cartografía de la época demostraba conocimiento sobre las características más importantes de la costa este de Groenlandia. De esta forma, estableció que los derechos del rey sobre Groenlandia eran de tal naturaleza que le otorgaban soberanía sobre esta en su totalidad y no solamente en relación con las áreas pobladas o colonizadas ${ }^{32}$. Dos días después de emitida la Opinión en el caso, Noruega revocó el decreto de 12 de julio de 1932.

\subsection{La consolidación de los derechos de Noruega}

Con base en la teoría de la contigüidad, Noruega reclamó soberanía sobre el archipiélago de Esvalbard (en adelante Esvalbard o Spitsbergen), la isla Oso y Jan Mayen.

Sin perjuicio de la invocación de la teoría, Noruega consolidaría su influencia decisiva en la zona en el siglo XIX como consecuencia de grandes esfuerzos diplomáticos.

Sobresale a este respecto la Conferencia de Expertos de Christiania de 1912, en donde representantes de Noruega, Suecia y Rusia elaboraron y suscribieron un instrumento de derecho internacional mediante el cual se le otorgó el carácter de terra nullius al grupo de islas que conforman el archipiélago de Esvalbard. También la denominada Conferencia de Spitzbergen de 1914, en la que estuvieron representados Noruega, Suecia, Rusia, Alemania y los Estados Unidos de América. La Primera Guerra Mundial suspendería la Conferencia y, por lo tanto, el reconocimiento de la soberanía de Noruega sobre el archipiélago de Esvalbard y la isla Oso solo se concretaría en la Conferencia de París de 9 de febrero de 1920. La declaración fue en todo caso respetuosa de las históricas prácticas en la zona y, por ende, reconoció de manera concomitante el derecho de los nacionales de los Estados signatarios, incluyendo a los de la ausente URSS, a continuar cazando y pescando en el archipiélago y en sus aguas adyacentes.

\subsection{La consolidación de los derechos de Canadá}

Canadá invocó la teoría de las regiones de atracción en su intención de establecer su soberanía sobre las islas e islotes del denominado Archipiélago Ártico ${ }^{33}$. El propósito de Canadá era consolidar su título sobre las tierras al norte

\footnotetext{
${ }^{32}$ PCIJ: Ser. A/B No 53, 1933, pp. 62-64.

${ }^{33}$ Baffin Island, Cocburn Island, Grant Land, Grinnel Land, North Lincoln, North Devon, North Somerset, Prince of Wales Land, Victoria Land, Prince Albert's Land, Banks Land, Island of St. Patrick, Melville Island, Peary Island, etc.
} 
de su masa continental, siendo claro que el descubrimiento de las formaciones insulares, sin ocupación hasta 1919, había corrido por cuenta de exploradores británicos y estadounidenses. Más allá de la invocación de la teoría, Canadá fundamentaba su reclamo en patrullajes, establecimiento de oficinas postales y la construcción de pistas de aterrizaje en las islas precitadas.

El senador Pascal Poirier reclamó ante el Senado canadiense una declaración formal de posesión de las islas por parte del Gobierno. Las pretensiones territoriales de Canadá en el Ártico se verían reforzadas con la denominada "Teoría de los Sectores". Pascal Poirier defendió la teoría señalando que mediante ella se hacía posible una división territorial con apego a criterios estrictamente geográficos. Según Poirier, el carácter natural de esta forma de división permitiría evitar conflictos y diferendos entre las potencias concernidas, las cuales muy seguramente aceptarían una división que implicara la extensión de sus posesiones hacia el Polo Norte. Intencional o accidentalmente, Pascal Poirier omitió hacer referencia a las consecuencias derivadas de la diferencia en la extensión y proyección de las costas de los Estados árticos, diferencia que sin lugar a dudas beneficiaría a Canadá, pero también a la entonces URSS.

Para el momento de la formulación efectuada por Pascal Poirier, el Departamento del Interior de Canadá ya había publicado dos mapas en consonancia con las nuevas reivindicaciones en el Ártico ${ }^{34}$.

La estructuración y verdadera modelación de una teoría correría a cargo de los asesores jurídicos y doctrinantes a fines de la URSS. La teoría de los sectores se plasmaría en el Decreto del Comité Ejecutivo de la Unión de 15 de abril de 1926 bajo el siguiente tenor: "Todas las tierras e islas, tanto las descubiertas como las que podrían serlo en el futuro, que no conforman en el momento de la publicación del presente decreto el territorio de otro Estado extranjero reconocido por la URSS, localizadas en Océano Ártico norte, al norte de las costas de la URSS hasta el Polo Norte entre el meridiano $32^{\circ} 04^{\prime} 35^{\prime \prime}$ E de longitud, de Greenwich, a lo largo del costado oriental de la Bahía de Vaida a través del hito triangular en Cabo Kekurskii, y el meridiano $168^{\circ} 49^{\prime} 30^{\prime \prime}$ W. de longitud desde Greenwhich... se proclaman como territorio de la URSS"35. [Traducción libre].

La exclusión de las tierras reconocidas como de propiedad de otro Estado se hizo con el propósito de no afectar el archipiélago de Esvalbard, cuya soberanía se le reconocía a Noruega.

\footnotetext{
${ }^{34}$ Pharand (2009), p. 10.

${ }^{35}$ BUTLER (1978), p. 72.
} 
La expedición del explorador MacMillian -con miras a la construcción de una base aérea- a las islas del Archipiélago Ártico daría lugar a un importante cruce de notas diplomáticas entre el Gobierno británico y el de los Estados Unidos de América, que a la postre consolidaría la posición canadiense en relación con la soberanía sobre el Archipiélago. Tras conocer la advertencia del Gobierno canadiense de salir a la defensa de las islas árticas si se aprobaban sobrevuelos sobre ellas, Estados Unidos de América renunció a sus pretensiones y procedió al reconocimiento de los derechos soberanos de Canadá en esa zona ${ }^{36}$.

\subsection{Consolidación de los derechos de Estados Unidos de América}

La única proyección de ese Estado en el Ártico vino a generarse con la compra de Alaska en $1867^{37}$. La Oficina del Historiador del Departamento de Estado de los Estados Unidos de América alude a la compra de Alaska como el punto final de las pretensiones rusas de expandir su comercio y asentamientos en la costa pacífica de Norteamérica. Asimismo, caracteriza la compra como una contribución a la consolidación de Estados Unidos como una potencia en la región Asia-Pacífico. La cesión onerosa tendría lugar por un valor de US\$ 7,200.000 y sería considerada por algunos como una verdadera extravagancia $^{38}$. Desde el punto de vista soviético, parece existir consenso en que la venta fue una consecuencia derivada de las importantes pérdidas económicas generadas por la infructuosa guerra de Crimea y la imposibilidad de seguir sufragando los importantes costos de los asentamientos en Alaska.

\subsection{La consolidación de derechos de la Unión de Repúblicas Socialistas Soviéticas}

La activa participación de la URSS en el Ártico, inter alia, a través de exploraciones e intentos de establecimiento, explica la extensión e intensidad de sus pretensiones soberanas en esta área ${ }^{39}$.

Aunque la teoría de las regiones de atracciones fue invocada por la entonces URSS para reclamar las islas al norte de sus costas y hasta el Polo Norte, lo cierto es que para 1930 esta ya había podido establecer asentamientos permanentes en unas, estaciones meteorológicas en otras, y en todo caso, formaciones insulares

\footnotetext{
${ }^{36}$ FAUCHILle (1925), pp. 661-662.

${ }^{37}$ Disponible en: https://history.state.gov/milestones/1866-1898/alaska-purchase [visitado el 3.10.2017].

${ }^{38}$ MiLLeR (1925), p. 58.

${ }^{39}$ Olenicoff (1972), p. 11.
} 
como Nnovaya e isla Wrangel fueron visitadas periódicamente por la marina y aeronaves soviéticas y explotadas por pescadores y cazadores ${ }^{40}$.

Por esta razón, no sorprende que los actos domésticos de apropiación puedan rastrearse hasta las primeras décadas del siglo XIX. Es así como en 1821, el emperador Alexander I emitió un ucase, proclamación con fuerza de ley del zar, mediante el cual alegó derechos exclusivos sobre las aguas del mar de Bering. Ante la protesta de Inglaterra y los Estados Unidos, se celebraron los tratados de 1824 -con los Estados Unidos de América-y de 1825 -con el Reino Unido-.

\section{El artículo 76 de la Convención de Naciones Unidas sobre el Derecho del Mar}

El interés reciente sobre la validez de las reclamaciones marítimas más allá de las 200 millas náuticas tiene como referente mediático relevante la expedición rusa de 2 de agosto de 2007 en la que, mediante el uso de un sumergible no tripulado, se incrustó una bandera rusa en el lecho de la cordillera Lomonosov a aproximadamente 4.200 metros de profundidad. El Ministro de Relaciones Exteriores canadiense descartó el valor jurídico de la actuación rusa y sobre ella indicó: "This isn't the 15th century. You can't go around the world and just plant flags and say 'We're claiming this territory" 41 [Este no es el siglo XV. Uno no puede andar por el mundo incrustando banderas y decir 'Reclamamos este territorio'"

En sus intervenciones posteriores, los diplomáticos y científicos rusos manifestaron su acuerdo con la imposibilidad de actuar de manera unilateral en el Ártico y su deseo por acatar las reglas previstas en la Convención. En este contexto, resulta importante diferenciar los actos que implican reclamaciones territoriales frente a actuaciones lícitas de otra naturaleza, entre ellas, las expediciones de carácter científico que los Estados árticos están llevando a cabo con el propósito de establecer la extensión natural de sus márgenes continentales ${ }^{42}$. Las expediciones científicas rusas más recientes han tenido como objetivo la recolección de información que permita establecer conexiones entre las crestas Lomonosov y Alpha-Mendelev con su margen continental, particularmente en Siberia ${ }^{43}$.

Sin perjuicio del hecho anecdótico protagonizado por el sumergible ruso, las reclamaciones árticas sobre la plataforma continental más allá de las 200

\footnotetext{
40 LAKHTINe (1930), p. 707.

41 "Canada mocks Russia's '15th century' Arctic claim". Disponible en: http://www.liveleak.com/ view? $i=f 75 \_1186243067$. [Visitado el 3.10.2017].

42 Potrs et al. (2008), p. 162.

${ }^{43}$ MACNAB (2006), pp. 3-4.
} 
millas náuticas no contradicen el derecho internacional ${ }^{44}$. Por el contrario, tras analizar la práctica estatal en la zona, autores como Potts y Schofield concluyen que todos los Estados árticos parecen estar actuando de conformidad con la normativa aplicable ${ }^{45}$.

La principal norma en este contexto es el numeral $1^{\circ}$ del artículo 76 de la Convención, el cual reconoce a los Estados el derecho a una plataforma continental "a todo lo largo de la prolongación natural de su territorio hasta el borde exterior del margen continental".

El artículo 76 de la Convención consagra para sus Estados partes las fórmulas para el establecimiento del borde exterior del margen continental (numeral $\left.4^{\circ}\right)$, los limitantes a la línea que fija el punto exterior (numerales $5^{\circ}, 6^{\circ}$ y $7^{\circ}$ ), así como el procedimiento para la delineación del punto exterior del margen continental (numeral $8^{\circ}$ ). El método previsto en el inciso i) literal a) del numeral $4^{\circ}$ se fundamenta en la constatación de la extensión de la sedimentación y responde a la denominada "fórmula Gardiner"46; el del inciso ii) consagra una metodología en función de la distancia con respecto al pie del talud continental y responde a la denominada "fórmula Hedberg" ${ }^{47}$. Tal y como lo expresan Smith y Taft, las fórmulas son de aplicación alternativa con miras a maximizar la extensión de la titularidad estatal ${ }^{48}$.

Cuando el Estado costero considera que el borde exterior de su plataforma continental se ubica más allá de las 200 millas náuticas, este deberá presentar la información y evidencia que acreditan este hecho ante la Comisión de Límites sobre la Plataforma Continental (Comisión), la cual emitirá una recomendación sobre la base de la evidencia científica presentada. La Convención dispone con claridad que "Il]os límites de la plataforma que determine un Estado ribereño tomando como base tales recomendaciones serán definitivos y obligatorios". A este respecto, Elferink señala que la competencia para establecer el límite exterior del margen continental es del Estado costero y que la Comisión no puede imponer su posición ${ }^{49}$. Asimismo, indica que la Comisión carece de

\footnotetext{
${ }^{44}$ JeNSEN (2015), p. 241.

${ }^{45}$ Potts et al. (2008), p. 161.

46 “i) Una línea trazada, de conformidad con el párrafo 7, en relación con los puntos fijos más alejados en cada uno de los cuales el espesor de las rocas sedimentarias sea por lo menos el $1 \%$ de la distancia más corta entre ese punto y el pie del talud continental".

47 “ii) Una línea trazada, de conformidad con el párrafo 7, en relación con puntos fijos situados a no más de 60 millas marinas del pie del talud continental".

${ }^{48}$ Sмiтн et al. (2000), en Соок et al. (Eds.), p. 19.

${ }^{49}$ ElFERINK (2011), párr. 4.
} 
competencia para evaluar si el Estado ha establecido el límite exterior del margen continental de conformidad con su recomendación ${ }^{50}$.

En todo caso, Michael Sheng-ti Gau explica que el límite establecido de conformidad con el numeral $8^{\circ}$ del artículo 76 de la Convención se torna vinculante para el Estado costero, pero carece de este carácter o de oponibilidad frente a terceros Estados ${ }^{51}$. En su consideración, cualquier otra interpretación implicaría un desconocimiento de las disposiciones sobre delimitación marítima prevista en el numeral $1^{\circ}$ del artículo 83 de la Convención, así como en el numeral $10^{\circ}$ de su artículo $76^{52}$.

Sin perjuicio de las consideraciones doctrinales al efecto, el procedimiento previsto en el artículo 76 de la Convención ya ha sido objeto de pronunciamiento por parte de la Corte Internacional de Justicia (la Corte).

La jurisprudencia reciente de la Corte permite señalar que el agotamiento del procedimiento previsto en el artículo 76 de la Convención para el establecimiento del borde exterior del margen continental hace parte del objeto y fin de la Convención. Así lo estableció en el párrafo 126 de su fallo de 19 de noviembre de 2012 en el Diferendo Territorial y Marítimo (Nicaragua c. Colombia), para clarificar que aún en sus relaciones con Estados que no han ratificado la Convención, el Estado Parte "no está relevado" de presentar información sobre la ubicación del borde exterior de su margen continental ante la Comisión de Límites de la Plataforma Continental, hasta obtener una revisión por parte de esta ${ }^{53}$. No obstante, en su más reciente decisión de 17 de marzo de 2016, la Corte consideró que, atendiendo al carácter independiente de las funciones de la Comisión y de la Corte, esta podía proceder a la delimitación marítima de la plataforma continental sin que previamente se hubiera agotado el procedimiento ante aquella ${ }^{54}$.

El incorrecto establecimiento del borde exterior del margen continental no solo podría repercutir en una apropiación ilegal de los recursos de la Zona, sino además en la afectación de los derechos de un Estado costero dentro de sus 200 millas náuticas. En el primer caso, el numeral $1^{\circ}$ del artículo 137 de la Convención prohíbe el ejercicio de soberanía o de derechos soberanos

\footnotetext{
${ }^{50}$ ELFERINK (2011), párr. 5.

${ }^{51}$ Sheng-Ti Gau (2011), p. 7. En el mismo sentido, McDorman (2002), p. 315.

52 También McDorman (2002), p. 315.

${ }^{53}$ CIJ: Judgment, I.C.J. Reports 2012, pp. 668-669, párr. 126.

${ }^{54}$ CIJ: Judgment, I.C.J. Reports 2016, p. 37, pará. 114.
} 
sobre la Zona o sus recursos naturales ${ }^{55}$. Para el segundo caso, el artículo 76 y su normativa complementaria previeron disposiciones específicas para evitar que el funcionamiento de la Comisión resultase afectado por la existencia de disputas marítimas y territoriales pendientes ${ }^{56}$.

Sobre este último particular debemos recordar que, de conformidad con el numeral $10^{\circ}$ del artículo 76 de la Convención, "las disposiciones de este artículo no prejuzgan la cuestión de la delimitación de la plataforma continental entre Estados con costas adyacentes o situadas frente a frente". Según lo prevé esta disposición, la Comisión no dispone de facultades en relación con la delimitación marítima de las áreas de superposición más allá de las 200 millas náuticas. Estas consideraciones explican el contenido del artículo $5^{\circ}$ (a) del Anexo I a las Reglas de Procedimiento de la Comisión, el cual le prohíbe a la Comisión calificar la pretensión en el evento en que exista una disputa territorial o marítima ${ }^{57}$.

A la luz de las consideraciones introductorias anteriores, se analizan a continuación las reclamaciones de los Estados árticos en relación con la plataforma continental más allá de las 200 millas náuticas. El propósito principal de esta aproximación no es avaluar el contenido de las reclamaciones formuladas por cada Estado, sino evidenciar que, en sus nuevas pretensiones marítimas, los Estados árticos se someten al imperio del derecho y apelan a la cooperación como herramienta para la consolidación de sus nuevos derechos marítimos de forma pacífica.

\section{Las reclamaciones de los Estados árticos}

\subsection{La reclamación de la Federación Rusa}

De conformidad con el Resumen Ejecutivo de la reclamación de 20 de diciembre de $2001^{58}$, la pretensión rusa comprende áreas localizadas en la región ártica, particularmente en el Océano Ártico Central y en el mar de Barents. Rusia alega que su prolongación natural se extiende más allá de las 200 millas náuticas en cuatro áreas, a saber, el mar de Barents, el mar de Bering, el mar Okhotsk y el Océano Ártico Central. El fundamento geológico de su reclamación reside en las crestas Lomonosov y Alpha-Mendelev, que según Rusia constituyen una prolongación natural del margen continental de Siberia, la cual se

\footnotetext{
${ }_{55}^{5}$ Sobre la función de la Comisión de Límites para prevenir la usurpación estatal de la Zona o de sus recursos naturales ver v.gr., SHenG-TI Gau (2001), p. 5; Mcnab (2004), p. 11.

${ }^{56}$ KUNOY (2006), p. 468.

${ }^{57}$ CLCS (2008).

${ }^{58}$ CLCS (2001-Rusia).
} 
extiende a lo largo del Océano Ártico cubriendo los márgenes de Groenlandia y Norteamérica ${ }^{59}$.

Canadá se mostró prudente frente al reclamo de Rusia. Tras señalar que requería de mayor información en relación con los datos científicos que soportaron la reclamación, procedió a diferenciar entre el trámite ante la Comisión y las funciones de esta y la cuestión de la delimitación marítima entre los Estados en el Océano Ártico ${ }^{60}$. También pidió que su silencio no fuera interpretado como una forma de consentimiento o aquiescencia. En sentido similar, Dinamarca expresó su interés en obtener mayor información sobre la data científica y diferenció las funciones de delineación ante la Comisión de la delimitación marítima por acuerdo entre las partes o ante un tribunal internacional, en particular, en el área de eventual superposición en Groenlandia ${ }^{61}$.

Noruega enmarcaría sus interrogantes y cuestionamientos en el párrafo 5 (a) del Anexo I de las Reglas de Procedimiento de la Comisión y por lo tanto, advirtió que se encontraban pendientes asuntos relativos a la delimitación marítima entre esta y Rusia en el mar de Barents. No obstante, bajo los términos de la misma disposición, Noruega expresaría su consentimiento a la revisión de la reclamación rusa por parte de la Comisión.

Las observaciones de Estados Unidos de América, Estado que hasta el día de hoy no es parte de la Convención, se dirigieron a visibilizar errores técnicos y un presunto no acatamiento de los criterios y reglas contenidos en el artículo 76 de la Convención ${ }^{62}$. En todo caso, en sintonía con lo expresado por Canadá y Dinamarca, Estados Unidos de América manifestó que no podía pronunciarse con autoridad frente al reclamo ruso dadas las limitantes en el acceso a la data científica ${ }^{63}$.

La consideración de la reclamación rusa fue incluida en la agenda de la décima sesión de la Comisión que se celebró en Nueva York entre el 25 de marzo y el 12 de abril de 2002. La presentación de la pretensión corrió a cargo de Ivan Gloumov, ministro encargado de Recursos Naturales de la Federación Rusa, quien se refirió a los comentarios de los Estados árticos, así como a uno elevado por Japón, y expresó que estos no constituían obstáculos para el análisis de la reclamación por parte de la Comisión ${ }^{64}$. La Comisión llamó al establecimiento

\footnotetext{
${ }^{59}$ Pharand (1969), pp. 214-216.

${ }^{60}$ CLCS (2002-Canadá).

${ }^{61}$ CLCS (2001-Dinamarca).

${ }^{62}$ CLCS (2002-Estados Unidos de América).

${ }^{63}$ Murphy (2005), p. 123; Jares (1999), p. 1287.

${ }^{64}$ CLCS (2002-Chairman).
} 
de una Subcomisión y ordenó que ningún miembro de esta fuera nacional de un Estado con el que Rusia pudiera tener una disputa ${ }^{65}$.

El 14 de junio de 2002, la Subcomisión completó su deliberación, emitió una recomendación y la envió para que fuera analizada en la decimoprimera sesión de la CLCS. La Comisión emitió una respuesta indicando que Rusia debía presentar una pretensión nueva y revisada ${ }^{66}$. De la información pública es posible colegir que esta le sugirió a la Federación Rusa presentar una reclamación revisada en relación con las áreas de supuesta prolongación localizadas en el Océano Ártico Central. En relación con las áreas ubicadas en el mar de Bering y en el mar de Barents, le recomendó que tan pronto como entraran en vigor los acuerdos de delimitación con Noruega, le transmitiera las cartas y coordenadas de las líneas de delimitación, con miras a analizar la forma en que estas describen el borde exterior del margen continental más allá de las 200 millas náuticas ${ }^{67}$.

Pese a constituir un asunto esencial en su política exterior, la decisión de la Comisión no ha generado traumatismos excesivos ni modificaciones sustanciales en las dinámicas y relaciones internacionales de Rusia vis a vis con sus vecinos árticos ni frente a la Comisión. Como lo pone de presente Baker, más allá de manifestaciones razonables de descontento frente a la decisión de la Comisión, es de público conocimiento que la Federación Rusa adelanta las labores y trabajos tendientes a presentar una reclamación revisada y trabaja con sus vecinos para el efecto sobre la base del texto de las Directrices de la Comisión ${ }^{68}$. Así lo había anticipado la Federación Rusa ante la Comisión, pues en su reclamación ya había advertido que la evidencia presentada era provisional y contingente a una mayor precisión del borde exterior como resultado de las labores de negociación y cooperación científica con sus vecinos.

Sobre el particular, corresponde expresar que aunque es posible encontrar literatura científica que alude a la existencia de rupturas geomorfológicas sustanciales en áreas frente a las costas rusas, las cuales podrían considerarse interrupciones en la continuidad del margen continental ${ }^{69}$, lo cierto es que no existe consenso entre la comunidad geológica y científica que intenta determinar

${ }^{65}$ CLCS (2002-Chairman), pars. 13 y 15.

${ }^{66}$ Secretary-General (2002), pars. 27-41.

${ }^{67}$ Secretary-General (2002), pars. 39 y 41.

${ }^{68}$ BAker (2010), p. 258. Baker cita a RiddelL-Dixon (2008), p. 343.

${ }^{69}$ MaCnab (2008), p. 223, en Matz-LüCK (2009), p. 250. 
si crestas como la Lomonosov constituyen una prolongación natural del margen continental ruso ${ }^{70}$.

\subsection{La reclamación del Reino de Noruega}

Noruega presentó una reclamación parcial ante la Comisión el 27 de noviembre de $2006^{71}$. Con relevancia para el presente escrito, la reclamación comprende áreas ubicadas en el Océano Ártico.

Sobre la base del Resumen Ejecutivo, Dinamarca expresó que ni su Gobierno ni las autoridades gubernamentales de Groenlandia objetaban la reclamación en los términos del párrafo 5 (a) del Anexo I de las Reglas de Procedimiento de la Comisión. En todo caso, recordaron que la cuestión de la delineación del borde exterior del margen continental no prejuzga ni afecta la cuestión de la delimitación marítima, ni precavía una eventual reclamación danesa en relación con la prolongación de Groenlandia más allá de las 200 millas náuticas ${ }^{72}$.

Rusia sí invocó el contenido del párrafo 5 (a) para aludir a la existencia de procedimientos de delimitación pendientes con Noruega. No obstante, tras recordar que la Comisión había instruido a Rusia a enviar las cartas y demás documentos sobre una eventual delimitación, esta manifestó su consentimiento al análisis de la reclamación noruega ${ }^{73}$.

La presentación de la reclamación fue efectuada el 2 de abril de 2007 por parte de Rolf Fife, director general de la Oficina de Asuntos Legales del Ministerio de Relaciones Exteriores de Noruega. El representante clarificó que en la estructuración de la reclamación se habían efectuado diversas labores de compartición, adquisición y procesamiento de datos con sus pares en las instituciones técnicas competentes en Rusia y Dinamarca. Asimismo, se aludió a trabajos de cooperación para la obtención de datos con instituciones científicas en Alemania, Estados Unidos, Rusia y Suecia ${ }^{74}$.

De conformidad con su práctica, la Comisión señaló que la reclamación de Noruega se abordaría mediante el establecimiento de una Subcomisión ${ }^{75}$. El 13 de marzo de 2009, la Subcomisión presentó sus recomendaciones ante la Comisión. Noruega solicitó la celebración de una reunión con los expertos de la Subcomisión. Durante la reunión, el representante Fife recordó por una

\footnotetext{
${ }^{70}$ MACNAB et al. (2006), p. 311.

${ }^{71}$ CLCS (2009).

72 Naciones Unidas (2007-Dinamarca).

${ }^{73}$ Naciones Unidas (2007-Rusia).

${ }^{74}$ CLCS (2007-Chairman).

${ }^{75}$ Jares (1999), p. 1294.
} 
última vez que la reclamación noruega estaba precedida por un importante trabajo de cooperación con sus Estados vecinos.

El 27 de marzo de 2009, la Comisión emitió su recomendación por consen$\mathrm{so}^{76}$. La Comisión consideró que la prolongación natural del margen continental, tanto de Rusia como de Noruega, sí se extiende más allá de las 200 millas náuticas en el área del "Loop Hole"77. La Comisión señaló que la información en relación con el "Loop Hole" era suficiente para satisfacer los requerimientos de una reclamación sobre la plataforma continental más allá de las 200 millas náuticas. En todo caso, aconsejó a Noruega proceder a la delimitación -con la Federación Rusa- de la plataforma continental más allá de las 200 millas náuticas en esta área, mediante acuerdo, pero con la seguridad de que los dos Estados disponen de la titularidad ("entitlement") a una plataforma continental más allá de las 200 millas náuticas en esta área del mar de Barents ${ }^{78}$.

\subsection{La reclamación de Canadá}

El 6 de diciembre de 2013 Canadá presentó ante la Comisión de Límites una reclamación parcial con información que acredita su titularidad a una plataforma continental más allá de las 200 millas náuticas. La reclamación no contiene información en relación con los límites de su plataforma continental más allá de las 200 millas náuticas en el Océano Ártico. Según lo señala Canadá, esta será presentada en una fecha posterior. Sin perjuicio de lo anterior, es posible presumir y anticipar un comportamiento semejante para el establecimiento efectivo de sus derechos en el Océano Ártico y, por lo tanto, su sometimiento al imperio del derecho en la sustanciación y defensa de sus nuevas pretensiones marítimas. Según se lee en la Declaración sobre la Política Exterior de Canadá en el Ártico: "Vehículos submarinos autónomos -con tecnología canadiense en su núcleo- están siendo utilizados para recolectar la data requerida. Canadá está invirtiendo de manera significativa para asegurar el logro del reconocimiento internacional de la totalidad de la extensión de su plataforma continental en los océanos Ártico y Atlántico"779. [Traducción libre].

En la Declaración se reconoce que los demás Estados árticos también tienen plataformas continentales más allá de las 200 millas náuticas. Según se informa

\footnotetext{
${ }^{76}$ CLCS (2009-Noruega).

${ }^{77}$ CLCS (2009-Chairman).

${ }^{78} \mathrm{CLCS} / 62$ (2009), par. 24.

79 "Statement on Canada's arctic foreign policy. Exercising sovereignty and promoting Canada's northern strategy abroad", p. 9. Disponible en: http://www.international.gc.ca/arctic-arctique/assets/ pdfs/canada_arctic_foreign_policy-eng.pdf. [Visitado el 3.10.2017].
} 
en la Declaración, para maximizar la recolección de evidencia en un ambiente físico desafiante, Canadá promueve el intercambio de información. Por último, la Declaración deja claro que cualquier evento de superposición con los derechos de los Estados vecinos será resuelto a través de medios pacíficos y de conformidad con el derecho internacional ${ }^{80}$.

Más allá de la Declaración y en confirmación de la tesis principal del autor, Canadá ha cooperado por varios años con los Estados Unidos con miras a recolectar información que le permita sustanciar la futura reclamación ante la Comisión. Sobre este particular, Betsy Baker pone de presente que desde el 2009 el rompehielos canadiense "Louis S. St. Laurent" y el de los Estados Unidos "ISCGC Healy" han navegado de manera mancomunada el Océano Ártico con el propósito de mapear su plataforma continental ${ }^{81}$. Este hecho es altamente relevante, pues representa una instancia de cooperación diplomática y científica entre un Estado parte de la Convención y un Estado no parte, para la consecución pacífica de un bien común.

\subsection{La reclamación del Reino de Dinamarca}

El 15 de diciembre de 2014, Dinamarca presentó ante la Comisión información en relación con el borde exterior de su margen continental más allá de las 200 millas náuticas contadas desde las líneas de base a partir de las cuales se mide la anchura de su mar territorial. La reclamación versa sobre el punto de extensión a partir de la "Plataforma Norte de Groenlandia". Según lo advierte Dinamarca, se trata de una reclamación parcial que presenta de forma conjunta con el Gobierno de Groenlandia.

La reclamación cubre un área de más o menos novecientos mil kilómetros cuadrados de plataforma continental en el Océano Ártico $(900.000$ km²), un área del tamaño de Francia y Alemania y más de 20 veces la misma Dinamarca ${ }^{82}$. En particular, el ministro de Relaciones Exteriores danés calificó la reclamación como un punto histórico de inflexión para el Reino ${ }^{83}$. Asimismo, el ministro puso de presente que, además de una labor de cooperación entre las autoridades

\footnotetext{
${ }^{80}$ Statement on Canada's Arctic foreign policy. exercising sovereignty and promoting Canada's northern strategy abroad", p. 10. Disponible en: http://www.international.gc.ca/arctic-arctique/assets/pdfs/ canada_arctic_foreign_policy-eng.pdf. [Visitado el 3.10.2017].

${ }^{81}$ BAKER (2010), pp. 57-59.

82 "Denmark to claim slice of continental shelf in Arctic Ocean". Disponible en: http://www.reuters. com/article/2014/12/15/us-denmark-arctic-idUSKBNOJTOS620141215. [Visitado el 3.10.2017].

83 "Demark and Greenland will today file a submission regarding the continental shelf north of Greeland". Disponible en: http://um.dk/en/news/newsdisplaypage/?newsid=71574e42-6115-4d169c8a-4c056f8603f3. [Visitado el 3.10.2017].
} 
danesas, se trata de un trabajo que involucra altos niveles de coordinación con los Estados vecinos en el Ártico.

\subsection{La situación de los Estados Unidos de América}

La decisión de no hacerse parte de la Convención le ha otorgado a los Estados Unidos de América un estatus diferente para el tratamiento de las reclamaciones de sus vecinos árticos más allá de las 200 millas náuticas, así como para la fundamentación de su pretensión. En efecto, en atención a que Estados Unidos no es parte de la Convención, no le es oponible un procedimiento específico para la delineación del límite exterior de su margen continental ${ }^{84}$, tampoco opera para este una fecha límite para la sustanciación de su pretensión.

Sin embargo, es esa posición diferenciada la que hace que la respuesta de los Estados Unidos frente a las reclamaciones de sus vecinos sea relevante y confirme la tesis planteada en el presente escrito.

En relación con la fundamentación de su pretensión marítima, es preciso hacer notar que desde 2002 Estados Unidos adelanta costosos trabajos para la determinación de la posibilidad de extender su plataforma continental más allá de las 200 millas náuticas. El Departamento de Estado reporta que desde 2003 la agencia federal para la Administración Nacional Oceánica y Atmosférica (NOAA por sus siglas en inglés) ha financiado por lo menos 14 proyectos de recolección de información batimétrica en cruceros de investigación científica, cinco de ellos en el Océano Ártico (2003, 2004, 2007, 2008 y 2009) y uno en el golfo de Alaska (2005). Como resultado, se han logrado recolectar más de un millón de kilómetros cuadrados de data batimétrica ${ }^{85}$.

En relación con las reclamaciones de sus vecinos, en particular, frente a la reclamación rusa, la actuación de Estados Unidos puede calificarse como respetuosa del derecho aplicable. Tratadistas como Alex G. Oude Elferink destacan que los términos de la objeción de Estados Unidos no tuvieron un propósito desestabilizador y pudo estar inspirada por el deseo de no afectar negativamente el estado general de sus relaciones diplomáticas con Rusia ${ }^{86}$.

\footnotetext{
${ }^{84}$ El 7 de octubre de 1994, el entonces Presidente Bill Clinton transmitió al Senado de los Estados Unidos de América el texto de la Convención de Naciones Unidas sobre el Derecho del Mar, junto con el Acuerdo de 1994 relativo a la Implementación de la Parte XI de la Convención. La ratificación de la Convención ha contado con la recomendación favorable del Comité de Relaciones Exteriores del Senado, así como por un amplio sector diplomático, ambiental y de las Fuerzas Armadas. Para un estudio sobre el particular: MATtLeR (2005), p. 33.

85 "U.S. Department of State, "Defining the Limits of U.S. Continental Shelf". Disponible en http:// www.state.gov/e/oes/continentalshelf/.

${ }^{86}$ Elferink (2009), pp. 546-548. [Visitado el 3.10.2017].
} 
De otra parte, es posible colegir que las objeciones de Estados Unidos de América se expresaron de forma constructiva con miras a la estructuración de una reclamación más acorde con los estándares y directrices previstos por la Comisión. Lejos de ser especulativa, esta consideración encuentra fundamento en la conclusión final de los Estados Unidos, en donde señaló que las recomendaciones de la Comisión solo podrían emitirse sobre la base de un alto nivel de certeza, por lo que esta no debía dudar en anunciar la necesidad de obtener mayor información por parte del Estado costero ni en expresar la obligación de continuar con el análisis y el debate.

\section{Desarrollos recientes en el Ártico}

Según se anticipó en los apartes introductorios de este trabajo, el calentamiento global y sus efectos derivados, entre ellos, la visualización de islas previamente cubiertas de hielo y la apertura de nuevas rutas marítimas, han prendido las alarmas sobre la importancia de consolidar los derechos históricos sobre las tierras e islas en el Océano Ártico, constituyéndose en combustible en la carrera de estos Estados hacia el establecimiento de derechos marítimos nuevos. En este sentido, algunos hechos recientes ponen a prueba la tesis principal del autor, según la cual, en el Ártico los derechos se consolidan a través de medios pacíficos.

La prensa ha abordado con especial atención la decisión de la Federación Rusa de fortalecer su presencia militar en el Ártico. Las notas periodísticas aluden a proyectos para establecer en 2018 una fuerza militar autosostenible, incluyendo fuerzas aéreas y zonas de entrenamiento ${ }^{87}$. Asimismo, se reportó el envío de 38.000 soldados, más de 100 aviones y cerca de 50 buques y 15 submarinos para poner a prueba la habilidad de despliegue y reacción de las fuerzas militares rusas desde sus ubicaciones en la Rusia continental ${ }^{88}$. Las sorpresivas actuaciones se verifican desde finales de 2014, con algunas tan recientes como las de marzo de 2015, cuando se ordenaron pruebas para verificar la capacidad de reacción y respuesta de la fuerza área y se realizaron ejercicios que involucraron más de 250 aviones en espacio aéreo cercano a algunos Estados bálticos miembros de la OTAN ${ }^{89}$. De otra parte, a inicios de octubre de 2014 se reportó el descubrimiento

\footnotetext{
${ }^{87}$ BarRabi (2015): "Russia To Build 'Self-Sufficient' Arctic Military Force By 2018 In Latest Sign of Buildup". Disponible en: http://www.ibtimes.com/russia-build-self-sufficient-arctic-military-force-2018latest-sign-buildup-1866430. [Visitado el 3.10.2017].

${ }^{88}$ ISACHENKOV (2015): "Russia launches massive Arctic military drills". Disponible en: http://www. newsobserver.com/article14572598.html. [Visitado el 3.10.2017].

${ }^{89}$ FARHI (2015): "NATO chief reacts to Russian surprise military exercises" en CBS News. Disponible en: http://www.cbsnews.com/news/nato-chief-reacts-to-russian-surprise-military-exercises/. [Visitado el 3.10.2017].
} 
de "Yaya", por parte de pilotos rusos. Se trata de una isla de unos quinientos metros cuadrados y de un metro de elevación sobre el nivel del mar. La isla se encuentra ubicada en el denominado "Laptev Sea", una vertiente del Océano Ártico de baja profundidad, temperaturas extremas y rodeada por tierras bajo soberanía rusa. El descubrimiento ha sido acompañado con la decisión de enviar personal militar a la isla ${ }^{90}$.

Los analistas exponen varias hipótesis que explican el comportamiento ruso, entre ellas, las recientes tensiones entre Rusia y los Estados de la OTAN con motivo de los alegatos de anexión en Crimea. Isabelle Mandraud, escribiendo para The Guardian, pone de presente el descubrimiento de Yaya, alude a las recientes actividades militares de Rusia en sus islas en el Ártico y señala que el interés renovado de la OTAN en la región podría traer de vuelta una atmósfera similar a la de la Guerra Fría ${ }^{91}$. Otros medios han recogido las declaraciones de Alexy Meshkov, ministro encargado de Relaciones Exteriores de Rusia, quien expresó preocupaciones por las actuaciones militares de la OTAN en áreas fronterizas ${ }^{92}$. En mayo de 2015 la OTAN inició actividades de entrenamiento militar en el Ártico, las cuales habían sido planeadas por varios meses e incluyeron la presencia de casi 100 aeronaves y 400 soldados. A la luz de estas actuaciones de parte y parte, un sector de los medios de comunicación describe las actuaciones rusas como una respuesta ante la actual situación internacional.

La reciente actividad militar rusa en el Ártico pone a prueba la tesis defendida. Sin embargo, el análisis de los observadores más cautos y prudentes coincide en gran medida con las declaraciones de los funcionarios rusos de alto nivel. El ministro de Defensa ruso, Sergei Shoigu, había justificado estas actuaciones experimentales en la necesidad de estar preparados ante nuevos retos y amenazas militares ${ }^{93}$. De otra parte, Dmitry Peskov, vocero del Kremlin, explicó que las actividades militares en el Ártico no responden a la situación internacional y, por el contrario, constituyen procesos estrictamente rutinarios

\footnotetext{
${ }^{90}$ Brown (2014): "Russia Activates Arctic Military". Disponible en: http://dailycaller.com/2014/10/21/ russia-activates-arctic-military/. [Visitado el 3.10.2017].

${ }^{91}$ MANDRAud (2014): "Russia prepares for ice-cold war with show of military force in the Arctic" en The Guardian. Disponible en: http://www.theguardian.com/world/2014/oct/21/russia-arctic-military-oil-gasputin. [Visitado el 3.10.2017].

${ }^{92}$ McLaughuin (2015): "Amid Nato exercises, Russia puts Northern Fleet on 'full alert'" en CNN. Disponible en: http://edition.cnn.com/2015/03/16/europe/russia-arctic-military-exercises/. [Visitado el 3.10.2017].

${ }^{93}$ McLaughuin (2015): "Amid Nato exercises, Russia puts Northern Fleet on 'full alert'" en CNN. Disponible en: http://edition.cnn.com/2015/03/16/europe/russia-arctic-military-exercises/. [Visitado el 3.10.2017].
} 
en la preparación y fortalecimiento de las Fuerzas Armadas rusas ${ }^{94}$. En consonancia, Jens Stoltenberg, secretario general de la OTAN, al tiempo que diferenció la situación en Ucrania, le dijo a "CBS News" que no consideraba que las actuaciones militares rusas en el Ártico representaran una amenaza inmediata contra ninguno de los 28 Estados miembros ${ }^{95}$. En todo caso, sugirió a los líderes rusos evitar actuaciones sorpresivas y los invitó a comportarse de manera más predecible para evitar malentendidos.

Más allá de las declaraciones de altos funcionarios rusos, la conducta efectiva demuestra que los nuevos retos derivados del calentamiento global y el derretimiento de los hielos se están resolviendo de forma pacífica. Sobre este particular resulta importante destacar que el incidente de 1985 en relación con el paso del buque USCG Polar Sea por el Paso Noroccidental en áreas consideradas por Canadá como aguas interiores se solucionó a través de un intercambio de notas entre el Departamento de Estado y el Ministerio de Relaciones canadiense y fue sucedido por la celebración del Acuerdo de 1988 sobre Cooperación Ártica ${ }^{96}$.

En relación con las nuevas reclamaciones sobre la plataforma continental, la actuación de los Estados árticos es diáfana en relación con su sometimiento al imperio del derecho y el recurso a la cooperación técnica y científica como herramienta para la realización y ejercicio de sus derechos marítimos. A través de la Declaración de Ilulissat de 2008, los Estados árticos manifestaron su compromiso con la solución pacífica de las controversias derivadas de la eventual superposición de áreas marítimas más allá del criterio de distancia ${ }^{97}$. A través de este tipo de instrumentos, los Estados árticos desarrollan el contenido del artículo 301 de la Convención, el cual obliga a hacer ejercicio de los derechos marítimos y cumplir con las obligaciones absteniéndose de recurrir a la amenaza o el uso de la fuerza de cualquier forma incompatible con los propósitos de la Carta de las Naciones Unidas.

Es en este contexto en el que deberá entenderse y ponderarse el valor de la actuación de la Federación Rusa de febrero de 2007, mediante la cual incrustó una bandera de titanio en el lecho marino del Océano Ártico. Lejos de tratarse de un intento de apropiación unilateral, la actuación debe valorarse como una hazaña desde el punto de vista técnico y científico para la comprensión de

\footnotetext{
94 "Russian army snap check not linked to international situation-Kremlin", Agencia rusa de noticias. Disponible en: http://tass.ru/en/russia/783001. [Visitado el 3.10.2017].

${ }^{95}$ FARHI (2015): "NATO chief reacts to Russian surprise military exercises" en CBS News. Disponible en: http:// www.cbsnews.com/news/nato-chief-reacts-to-russian-surprise-military-exercises/. [Visitado el 3.10.2017].

961852 UNTS 31529. Sobre el incidente de 1985 entre Canadá y Estados Unidos de América en relación con el anuncio del USCG Polar Sea de cruzar el Paso Noroccidental, ver Rothwell (2013), pp. 9-10.

${ }^{97}$ Koivurova (2011), p. 220.
} 
los componentes sedimentarios del lecho marino en un área históricamente vedada para el hombre ${ }^{98}$.

A este respecto resulta relevante observar que desde que fuera publicada la pretensión rusa sobre la plataforma continental más allá de las 200 millas náuticas, Canadá y Dinamarca han adelantado sondeos conjuntos de sísmica con el objetivo de determinar la conexión de Groenlandia o Canadá con la cordillera Lomonosov ${ }^{99}$. Canadá y Rusia habrían efectuado intercambios de información sobre aspectos similares. Por su parte, Macnab y Parson destacan la realización de conferencias en Rusia para abordar la cuestión de las "crestas submarinas" y reportan que en 2007 este Estado decidió hacer pública la evidencia incluida en su reclamación de $2001^{100}$. Los resultados de este esfuerzo y aproximación mancomunada encuentran una de sus máximas expresiones en la Carta Batimétrica Internacional del Océano Ártico ("International Bathymetric Chart of the Arctic Ocean"). La Carta constituye en sí misma un producto de la cooperación entre los Estados Árticos y nace del interés de estos con miras a dar cumplimiento al procedimiento del artículo 76 de la Convención.

\section{Conclusiones}

De conformidad con la evidencia empírica aportada en el presente escrito, fue posible confirmar la hipótesis inicial del autor. En efecto, las dinámicas históricas entre los Estados árticos reflejan aproximaciones altamente dialécticas, pacíficas y, por lo tanto, respetuosas de la igualdad soberana.

Así lo demuestra la posición adoptada por los Estados Unidos de América frente a la reclamación territorial canadiense sobre el archipiélago ártico, el grado de moderación demostrado por Canadá y la entonces URSS en la sustentación de sus pretensiones sobre las lejanas tierras árticas, así como el proceso de caracterización de Esvalbard como terra nullius y su posterior adjudicación a Noruega. El precedente en relación con Groenlandia no contradice la tesis del autor pues, como vimos, el decreto noruego de 10 de julio de 1931 no fue implementado sino hasta agotar varias instancias de negociación directa, y la decisión de la Corte Permanente de Justicia Internacional derivaría en la cesación inmediata de la presencia de Noruega.

Señalar que las actuales dinámicas de solución pacífica y aproximación cooperativa se inscriben y son consecuencia de la práctica histórica de los

\footnotetext{
98 Proels et al. (2008), p. 682; Matz-LüCK (2009), p. 251.

${ }^{99}$ BAKER (2010a), p. 269.

${ }^{100}$ MaCnAB et al. (2006), p. 312.
} 
Estados árticos es una afirmación ambiciosa. Sin embargo, a partir de un análisis global de los acontecimientos, una tal conclusión asoma como plausible.

A este respecto, la posición adoptada por la Federación Rusa frente a las decisiones de la Comisión no debe subestimarse. Su profunda significación reside en que, al versar sobre intereses de un altísimo contenido económico, Rusia hubiera podido alegar que las recomendaciones de la Comisión carecen de un carácter jurídicamente vinculante y, por lo tanto, son susceptibles de desatención sin que ello conlleve responsabilidad internacional por el hecho internacional ilícito. Una posición de desobediencia frente a lo manifestado por la Comisión solo hubiera constituido el preludio para una actuación unilateral más vigorosa y agresiva frente a la exploración y explotación de los valiosos recursos de la plataforma continental en el Océano Ártico. En este sentido, la decisión de publicación de la evidencia recolectada, la celebración de diversas conferencias internacionales para socializar su pretensión y las actividades de cooperación con Canadá y Dinamarca parecen obedecer al reconocimiento de la necesidad aún vigente de actuar en armonía con los Estados costeros vecinos. En pocas palabras, Rusia parece entender que, no obstante los efectos del cambio climático y los mayores avances de la ciencia, el espesor del hielo y las condiciones ambientales extremas del Ártico desaconsejan actuaciones estrictamente unilaterales $y$, por el contrario, siguen militando a favor de una actuación mancomunada y cooperativa para la realización efectiva de los derechos. Aunado a lo anterior, el sometimiento de Rusia al imperio del derecho no obstante la extensión de su reclamación inicial más allá de las 200 millas náuticas, nos permite recordar que la Teoría de los Sectores, así como las teorías de la contigüidad y de las regiones de atracción, terminarían siendo sucedidas por actuaciones propias del derecho internacional general aplicable a la adquisición y transferencia del territorio.

Por su parte, las manifestaciones del canciller danés permiten colegir que, en línea con la actuación noruega, Dinamarca socializó su proyecto de pretensión de manera previa con los terceros Estados posiblemente concernidos. Esta "práctica" ártica parece responder a una lectura inteligente y astuta del contenido del numeral $10^{\circ}$ del artículo 76 de la Convención y de las Reglas de Procedimiento de la Comisión. En efecto, el intercambio diplomático previo les ha permitido a los Estados árticos conocer, con antelación a la activación del procedimiento previsto en el numeral $8^{\circ}$ del artículo 76 de la Convención, preocupaciones y consideraciones que de otra forma se harían valer por sus vecinos en el marco del párrafo 5(a) del Anexo 1 a las Reglas de Procedimiento de la Comisión. De esta forma los Estados árticos han logrado reducir las posibilidades de que el procedimiento ante la Comisión se paralice como consecuencia de una manifestación de protesta u objeción, al tiempo que se abren las puertas a la futura 
delimitación marítima en condiciones de armonía y confianza mutua ${ }^{101}$. Esta práctica no es nueva en el Ártico y, por el contrario, reproduce materialmente las dinámicas de negociación y concesión de beneficios mutuos que entre 1912 y 1920 [Conferencias de Christiania, Spitzbergen y París] hicieron posible el reconocimiento de la soberanía de Noruega sobre Esvalbard y la isla Oso.

Así las cosas, no cabe duda de que el referente ártico debe trascender las fronteras de sus Estados costeros e irradiar sus efectos positivos en otras partes del globo en donde las pretensiones marítimas más allá de las 200 millas han generado inestabilidad. Tal es el caso del mar Caribe Occidental, en donde el estudio de la reclamación nicaragüense por parte de la Comisión se encuentra paralizado debido a la objeción conjunta de Costa Rica, Colombia y Panamá102. Más aún, en el actual litigio entre Nicaragua y Colombia ante la Corte Internacional de Justicia, la decisión de esta última de admitir el reclamo nicaragüense sin el agotamiento del trámite ante la Comisión derivó en la decisión del Presidente de Colombia de no comparecer en la fase de méritos del litigio ${ }^{103}$. En la práctica, la Comisión no podrá estudiar la reclamación nicaragüense hasta tanto Colombia no retire su objeción bajo el párrafo 5 (a) del Anexo I, y la Corte se adentrará en la resolución de una disputa en la que la participación del demandado, siendo esencial para la resolución efectiva de la controversia, no está asegurada. Nos encontramos, entonces, ante un verdadero nudo gordiano que solo parece poderse desatar, o mejor aún, evitar, a través de las prácticas cooperativas que hoy se encuentran firmemente asentadas en el Ártico.

A la luz de las consideraciones precedentes, la actuación de los Estados árticos, la histórica y la presente en la defensa de sus intereses nacionales, merece una especial atención y congratulación. Los Estados árticos enfrentaron con originalidad, pero sobre todo con responsabilidad y apego al derecho, los obstáculos que la permanencia y vasta extensión del hielo históricamente impusieron, y aún hoy siguen imponiendo, a la realización de sus pretensiones nacionales. Son un verdadero referente global para la resolución pacífica de las controversias más importantes.

101 CIJ: Judgment, I.C.J. Reports 2009, p. 101, párrs. 115-116; CIJ: Judgment, I.C.J. Reports 2012, pp. 190-193; CIJ: Judgment, I.C.J. Reports 2014, p. 61, párr. 180.

102 V. gr. KWIATKOWSKA (2013), p. 277.

103 "Declaración del Presidente de Colombia, Juan Manuel Santos, sobre decisiones de la Corte Internacional de Justicia de La Haya". Disponible en: http://es.presidencia.gov.co/discursos/Declaraciondel-Presidente-de-Colombia-Juan-Manuel-Santos-sobre-decisiones-de-la-Corte-Internacional-deJusticia-de-La-Haya. [Visitado el 12.02.2017]. 


\section{Bibliografía CitADA}

BAKER, Betsy (2010a): "Filing an Arctic Gap: Legal and Regulatory Possibilities for Canadian-U.S. Cooperation in the Beufort Sea", en: Vermont Law Review (vol. 34), pp. 57-120.

Baker, Betsy (2010b): "Law, Science, and the Continental Shelf: The Russian Federation and the Promise of Arctic Cooperation", en: American University International Law Review (vol. 25), pp. 251-281.

BRILMAYER, Lea \& KleIN, Nataly (2001): "Land and Sea: Two Sovereignty Regimes in Search of a Common Denominator", en: New York University Journal of International Law and Politics (vol. 33), pp. 703-768.

Brownlie, Ian (1998): Principles of Public International Law, $5^{\text {th }}$ ed. (Oxford, University Press).

Butler, William E. (1978): International Straits of the World: Northeast Arctic passage (Martinus Nijhoff Publishers, The Hague).

Chaturvedi, Sanjay (1996): The Polar Regions-A Political Geography (Chichester, John Wiley).

ElfERINK, Alex G. (2009): "Establishment of Outer Limits of the Continental Shelf beyond 200 Nautical Miles by the Coastal State: The Possibilities of Other States to Have an Impact on the Process", en: The International Journal of Marine and Coastal Law (vol. 24), pp. 535-556.

ElfEerink, Alex G. (2011): "Commission on the Limits of the Continental Shelf", en: Max Planck Encyclopedia of Public International Law, par. 4.

Fauchille, Paul (1925): Traité de Droit International Public, Vol. I, Part 2 (Paris). Feder, Barnaby J. (1978): "A Legal Regime for the Arctic", en: Ecology Law Quarterly (vol. 6, No 4), pp. 785-829.

FranCKX, Erik (1993): Maritime Claims in the Arctic-Canadian and Russian Perspectives (Boston-London, Martinus Nijhoff).

Grant, Sean D. (2010): Polar Imperative: A History of Arctic Sovereignty in Nort America (Vancouver, Douglas \& Mclntyre).

Hertell, Hans (2009): "Arctic Melt: The Tipping Point for an Arctic Treaty", en: Georgetown International Environmental Law Review (№ 21), pp. 565-591.

Holmes, Stephany (2008): "Breaking the Ice: Emerging Legal Issues in Arctic Sovereignty", en: Chicago Journal of International Law (Vol. 9), pp. 323-351. Jarashow, Mark et al. (2007): "UNCLOS and the Arctic: The Path of Least Resistance", en: Fordham International Law Journal (Vol. 30, No 5), pp. 1587-1652. 
JARES, Vladimir (1999): "The Continental Shelf Beyond 200 Nautical Miles: The Work of the Commission on the Limits of the Continental Shelf and the Arctic", en: Varderbilt Journal of Transnational Law (Vol. 42), pp. 1265-1305.

JENSEN, Oystein (2015): "The seaward limits of the continental shelf beyond 200 nautical miles in the Arctic Ocean: legal framework and state practice", en: Jensen, Christian \& Honneland, Geir, Handbook of the politics of the Arctics (Cheltenham \& Northampton, Edward Elgar Publishing).

KLeIN, Nataly (2006): "Provisional Measures and Provisional Arrangements in Maritime Boundary Disputes", en: International Journal of Marine \& Coastal Law (Vol. 21), pp. 423-460.

Kolvurova, Timo (2011): "The Actions of Arctic States Respecting the Continental Shelf: A Reflective Essay", en: Ocean Development and International Law ( No 42), pp. 211-226.

Kunor, Bjorn (2006): "A New Arctic Conquest: The Arctic Outer Continental Margin", en: Nordic Journal of International Law (Vol. 76, № 4), pp. 465-480.

LaGonI, Rainer (1984): "Interim Measures Pending Maritime Delimitation Agreements", en: American Journal of International Law (Vol. 78), pp. 345-368.

Lakhtine, W. (1930): "Rights Over the Arctic", en: American Journal of International Law (vol. 24), pp. 703-717.

KWIATKOWSKA, Barbara (2013): "Submissions to the UN Commission on the Limits of the Continental Shelf: The Practice of Developing States in Cases of Disputed and Unresolved Maritime Boundary Delimitations or Other Land or Maritime Disputes. Part One", en: The International Journal of Marine and Coastal Law (Vol. 24, № 4), pp. 615-679.

MACNAB, Ron (2004): "The Case for Transparency in the Delimitation of the Outer Continental Shelf in Accordance with UnClOs Article 76", en: Ocean Development \& International Law (Vol. 35, № 1), pp. 1-17.

MACnab, Ron \& Parson, Lindsay (2006): "Continental Shelf Submissions: The Record to Date", en: International Journal of Marine and Coastal Law (Vol. 21), pp. 309-322.

MARQués, Efrén G. (2010): “La Condición Jurídica del Ártico y la Antártica: un asunto pendiente en la agenda jurídico-política de las relaciones internacionales contemporáneas", en: Revista de Relaciones Internacionales de la UNAM (Vol. 107), pp. 39-65.

McDorman, Ted (2002): "The Role of the Commission on the Limits of the Continental Shelf: A Technical Body in a Political World", en: International Journal of Marine and Coastal Law (Vol. 17), pp. 301-324. 
MATTLER, Michael J. (2005): "The Law of the Sea Convention: A View from the U.S. Senate", en: Nordquist, Myron H. et al. (Eds.), International Energy Policy, The Arctic and The Law Of The Sea (Leiden, Martinus Nijhoff Publishers and VSP).

Matz-LüCK, Nele (2009): "Planting the Flag in the Arctic Waters: Russia's Claim to the North Pole", en: Gôttingen Journal of International Law (vol. 2), pp. 235-255.

Miller, David H. (1925): "Political Rights and the Arctic", en: Foreign Affairs (Vol. 4, No 1), pp. 47-60.

Moreno Quintana, Lucio M. (1963): Tratado de Derecho Internacional (Buenos Aires, Sudamericana).

Murphy, John F. (2004): The United States and the Rule of Law in International Affairs (Nueva York- Melbourne-Madrid, Cambridge University Press).

Murphy, Sean D. (2005): United States Practice in International Law (Nueva York-Ciudad del Cabo-Melbourne-Singapur-São Paulo, Cambridge University Press). Volumen II.

Newton, George B. (2005): "Coming to the Arctic: Oil, Ships, and Unclos Plus Risk and Research", en: NordQuist, Myron H. et al. (Eds.), International Energy Policy, the Arctic and the Law of the Sea (Leiden, Martinus Nijhoff Publishers and VSP), pp. 321-324.

Offerdal, Kristine (2014): "Interstate relations: the complexities of Arctic politics", en: Tamnes, Rolf \& Offerdal, Kristine (Eds.), Geopolitics and Security in the Arctic-Regional dynamics in a global world (London \& New York, Routledge), pp. 73-96.

OlenICOFF, S.M. (1972): Territorial Waters in the Arctic: the Soviet position (Santa Mónica, Rand).

Pharand, Donat (2009): Canada's Arctic waters in international law (Cambridge, University Press).

Pharand, Donat (1969): "Freedom of the Seas in the Arctic Ocean", en: University of Toronto Law Journal (vol. 19), pp. 210-233.

Potts, Tavis y SCHOFIELD, Clive (2008): "Current Legal Developments in the Arctic", en: The International Journal of Marine and Coastal Law (Vol. 23), pp. 151-176.

Prahasi Sharma, Surya (1997): Territorial Acquisition, Disputes, and International Law (Martinus Nijhoff Publishers, The Netherlands), p. 35.

Proels, Alexander \& Muller, Till (2008): "The Legal Regime of the Arctic Ocean", en: Heidelberg Journal of International Law (vol. 68 (6)), pp. 651-687. 
RAYFUSE, Rosemary (2007): "Melting Moments: The future of polar oceans governance in a warming world", en: Review of European Community and International Environmental Law (vol. 16 (2)), pp. 196-216.

Riddell-Dıxon, Elizabeth (2008): "Canada and Arctic Politics: The Continental Shelf Extension", en: Ocean Development and International Law (vol. 39 (4)), pp. 343-359.

RothwelL, Donald R. (1996): The Polar Regions and the Development of International Law (Cambridge, Cambridge University Press).

RothwelL, Donald R (2013): "Arctic Sovereignty and its Legal Significance for Canada", ANU College or Law Research Paper No 13-19.

SHAw, Malcolm (2013): "The International Court of Justice and the Law of Territory", en: TAMs, Christian \& SLOAN, James (Eds.), The Development of International Law by the International Court of Justice (Oxford, Oxford University Press).

SHAw, Malcolm (2014): International Law (Cambridge, Cambridge University Press).

SHeNG-TI GaU, Michael (2011): "The Commission on the Limits of the Continental Shelf as a Mechanism to Prevent Encroachment upon the Area", en: Chinese Journal of International Law (Vol. 10), pp. 3-33.

SHUSterich, Kurt M. (1984): "International Jurisdictional Issues in the Arctic Ocean", en: Ocean Development \& International Law (Vol. 14), pp. 235-272. SMITH, Robert y TAFT, George (2000): "Legal Aspects of the Continental Shelf", en: Cook, Peter J. y Carleton, Chris M. (Eds.), Continental Shelf Limits: The Scientific and Legal Interface (New Yord, Oxford University Press).

Timtchenko, Leonid (1997): "The Russian Arctic Sectorial Concept: Past and Present", en: American Journal of International Law (Vol. 50, № 1), pp. 29-35. VÁsquez, Modesto (1993): Derecho internacional público (México, Porrúa).

Young, Oran R. (2009): "Whither the Arctic? Conflict or Cooperation in the circumpolar north", en: Polar Record (Vol. 45, № 1), pp. 73-72.

\section{NORMAS JURÍDICAS CITADAS}

Acuerdo de 1988 sobre Cooperación Ártica [1852 UNTS 31529].

Convención de Naciones Unidas sobre el Derecho del Mar [1833 UNTS 3].

Convención de Viena sobre el Derecho de los Tratados [1155 UNTS 331].

"Agreement between Denmark and Norway Concerning The East Greenland Fisheries". 
JURISPRUDENCIA CITADA

Legal Status of Eastern Greenland, PCIJ, Ser. A/B No 53 (1933), pp. 23-24.

Island of Palmas case (The Netherlands/United States of America), Award of 4 April 1928, UNRIAA, vol. II, pp. 839, 845.

Barcelona Traction, Light and Power Company, Limited Judgment, I.C.J. Reports 1970, pp. 3, 32, pars. 33-34.

Western Sahara, Advisory Opinion, I.C.J. Reports 1975, p. 39, par. 79.

Continental Shelf (Libyan Arab Jamahiriya/Malta) Judgment, I.C.J. Reports 1985, p. 35, par. 39.

Territorial and Maritime Dispute between Nicaragua and Honduras in the Caribbean Sea (Nicaragua v. Honduras), I.C.J. Reports 2007 (II), p. 759, par. 319.

Maritime Delimitation in the Black Sea (Romania v. Ukraine), Judgment, I.C.J. Reports 2009, pars. 115-116.

Dispute concerning Delimitation of the Maritime Boundary between Bangladesh and Myanmar in the Bay of Bengal (Bangladesh/Myanmar), Judgment, 14 March 2012, p. 126, par. 429.

Questions relating to the Obligation to Prosecute or Extradite (Belgium v. Senegal), Judgment, I.C.J. Reports 2012, p. 422, p. 449, par. 68.

Territorial and Maritime Dispute (Nicaragua v. Colombia), Judgment, I.C.J. Reports 2012, p. 624, 669-770, par. 130.

Maritime Dispute (Peru v. Chile), Judgment, I.C.J. Reports 2014, par. 180.

Question of the Delimitation of the Continental Shelf between Nicaragua and Colombia beyond 200 nautical miles from the Nicaraguan Coast, Judgment, 2016, p. 37, par. 114.

\section{Documentos de Naciones Unidas-Comisión de Límites de la Plataforma Continental}

CLCS (2009): Recommendations of the Commission on the Limits of the Continental Shelf in Regard to the Submission Made by Norway in Respect of Areas in the Arctic Ocean, the Barents Sea and the Norwegian Sea on 27 November 2009. Disponible en: http://www.un.org/depts/los/clcs_new/ submissions_files/nor06/nor_rec_summ.pdf [visitado el 3/10/17].

CLCS (2009): "Directrices Científicas y Técnicas de la Comisión de Límites de la Plataforma Continental". Disponible en: http://daccess-dds-ny.un.org/doc/ 
UNDOC/GEN/N99/171/11/PDF/N9917111.pdf?OpenElement [visitado el $3 / 10 / 17]$.

CLCS (2007): Statement by the Chairman of the Commission on the Limits of the Continental Shelf on the Progress of Work in the Commission, CLCS/54. Disponible en: http://daccess-dds-ny.un.org/doc/UNDOC/GEN/N07/322/77/ PDF/N0732277.pdf?OpenElement [visitado el 3/10/17].

CLCS (2007): Permanent Mission of the Russian Federation, Notification Regarding Norway's Submission on the Continental Shelf Beyond 200 Nautical Miles to the Commission on the Limits of the Continental Shelf. Disponible en: http://www.un.org/depts/los/clcs_new/submissions_files/ nor06/rus_07_00325.pdf [visitado el 3/10/17].

CLCS (2007): Permanent Mission of Denmark, Notification Regarding Norway's Submission on the Continental Shelf Beyond 200 Nautical Miles to the Commission on the Limits of the Continental Shelf. Disponible en: http:// www.un.org/Depts/los/clcs_new/submissions_files/nor06/dnk07_00218.pdf [visitado el 3/10/17].

CLCS (2006): Submission by the Kingdom of Norway, Ref. No CLCS.07.2006. LOS. Disponible en: http://www.un.org/depts/los/clcs_new/submissions_files/nor06/clcs_07_2006_los_e.pdf [visitado el 3/10/17].

CLCS (2002): Statement by the Chairman of the Commission on the Limits of the Continental Shelf on the Progress of Work in the Commission, delivered to the Commission on the Limits of the Continental Shelf, CLCS/32, par. 10. Disponible en: http://daccess-ods.un.org/TMP/8666774.03450012.html [visitado el 3/10/17].

CLCS (2002): Permanent Mission of Canada to the United Nations - Notification Regarding the Submission made by the Russian Federation to the commission on the Limits of the Continental Shelf, CLCS.01.2001.LOS/CAN. Disponible en: http://www.un.org/depts/los/clcs_new/submissions_files/ rus01/CLCS_01_2001_LOS_CANtext.pdf [visitado el 3/10/17].

CLCS (2001): United States' Notification Regarding the Submission Made by the Russian Federation to the Commission on the Limits of the Continental Shelf, Ref. No CLCS.01.2001.LOS/USA. Disponible en: http://www.un.org/ depts/los/clcs_new/submissions_files/rus01/CLCS_01_2001_LOS_USAtext. pdf [visitado el 3/10/17].

CLCS (2001): Submission by the Russian Federation, Ref. No CLCS 01.2001. LOS. Disponible en: http://www.un.org/Depts/los/clcs_new/submissions_files/submission_rus.htm [visitado el 3/10/17]. 
CLCS (2001): Permanent Mission of Norway to the United Nations, Notification Regarding the Submission Made by the Russian Federation to the Commission on the Limits of the Continental Shelf, CLCS.01.2001.LOS/NOR. Disponible en: http://www.un.org/depts/los/clcs_new/submissions_files/rus01/ CLCS_01_2001_LOS_NORtext.pdf [visitado el 3/10/17].

CLCS (2001): Permanent Mission of Denmark to the United Nations, Notification Regarding the Submission Made by the Russian Federation to the Commission on the Limits of the Continental Shelf, CLCS.01.2001.LOS/DNK. Disponible en: http://www.un.org/Depts/los/clcs_new/submissions_files/rus01/ CLCS_01_2001_LOS_DNKtext.pdf [visitado el 3/10/17].

"Presentaciones en caso de controversia entre Estados con costas adyacentes o situadas frente a frente $u$ otras controversias territoriales o marítimas pendientes", abril de 2008, CLCS/40/Rev.1. Disponible en: http://daccess-dds-ny. un.org/doc/UNDOC/GEN/N08/309/26/PDF/N0830926.pdf?OpenElement [visitado el 3/10/17].

SG (2002): Report of the Secretary-General on the Oceans and the Law of the Sea, delivered to the General Assembly, A/57/57/Add.1, párrs. 27-41. Disponible en: http://daccess-ods.un.org/access.nsf/Get?Open\&DS=A/57/57\&Lang=E [visitado el 3/10/17].

\section{DOCUMENTOS ELECTRÓNICOS}

BarRabI, Thomas (2015): "Russia To Build 'Self-Sufficient' Arctic Military Force By 2018 In Latest Sign of Buildup". Disponible en: http://www.ibtimes. com/russia-build-self-sufficient-arctic-military-force-2018-latest-sign-buildup-1866430 [visitado el 3/10/17].

Brown, Melissa (2014): "Russia Activates Arctic Military". Disponible en: http:// dailycaller.com/2014/10/21/russia-activates-arctic-military/ [visitado el 3/10/17].

Canada mocks Russia's '15th century' Arctic claim. Disponible en: http://www. liveleak.com/view?i=f75_1186243067 [visitado el 3/10/17].

"Declaration on the Establishment of the Arctic Council" (1996). Disponible en: https://oaarchive.arctic-council.org/handle/11374/85 [visitado el 3/10/17].

Denmark to claim slice of continental shelf in Arctic Ocean. Disponible en: http://www.reuters.com/article/2014/12/15/us-denmark-arctic-idUSKBN0JTOS620141215 [visitado el 3/10/17].

Demark and Greenland will today file a submission regarding the continental shelf north of Greenland. Disponible en: http://um.dk/en/news/ 
newsdisplaypage/?newsid=71574e42-6115-4d16-9c8a-4c056f8603f3 [visitado el 3/10/17].

ENCYCLOPEDIA BRITANNICA: Disponible en: http://global.britannica.com/EBchecked/ topic/317469/Treaty-of-Kiel [visitado el 3/10/17].

FARHI, Arden (2015): "NATO chief reacts to Russian surprise military exercises", en CBS News. Disponible en: http://www.cbsnews.com/news/nato-chiefreacts-to-russian-surprise-military-exercises/ [visitado el 3/10/17].

ISACHENKOV, Vladimir: "Russia launches massive Arctic military drills". Disponible en: http://www.newsobserver.com/article14572598.html [visitado el 3/10/17].

MANDRAUD, Isabelle (2014): "Russia prepares for ice-cold war with show of military force in the Arctic", en The Guardian. Disponible en: http://www. theguardian.com/world/2014/oct/21/russia-arctic-military-oil-gas-putin [visitado el 3/10/17].

McLaughlin, Eliott C. (2015): "Amid NATO exercises, Russia puts Northern Fleet on 'full alert'", en CNN. Disponible en: http://edition.cnn.com/2015/03/16/ europe/russia-arctic-military-exercises/ [visitado el 3/10/17].

Oficina del Historiador del Departamento de Estado de los Estados Unidos de AMÉRICA, "Alaska purchase". Disponible en: https://history.state.gov/milestones/1866-1898/alaska-purchase [visitado el 3/10/17].

Statement on Canada's arctic foreign policy. Exercising Sovereignty and Promoting Canada's Northern strategy abroad, p. 9. Disponible en: http:// www.international.gc.ca/arctic-arctique/assets/pdfs/canada_arctic_foreign_policy-eng.pdf [visitado el 3/10/17].

Stauffer (2008): "U.S. Geological Survey Fact Sheet (2008-3049)", en Science for a Changing World. Disponible en: http://pubs.usgs.gov/fs/2008/3049/ fs2008-3049.pdf [visitado el 3/10/17].

U.S. Department of State, Defining the Limits of U.S. Continental Shelf. Disponible en: http://www.state.gov/e/oes/continentalshelf/ [visitado el 3/10/17]. 